\title{
The Effect of Early Mobilization on ICU and Hospital Length of Stay and Its Impact on the Cost of Care in Post-Open Heart Surgery Patients: A Randomized Control Trial (RCT)
}

\author{
Mohammed A Takroni, ${ }^{1, *}$, Ali Albarrati ${ }^{2}$, Tola Akomolafe ${ }^{3}$, and Mosleh Al Enazy \\ ${ }^{1}$ Department of Physical Rehabilitation, KFSHRC, Riyadh, KSA \\ ${ }^{2}$ Department of Physical and Health Science, College of Applied Medical Science, King Saud University, Riyadh, KSA \\ ${ }^{3} 306$ th FH, US Army \\ ${ }^{4}$ Department of Cardiovascular Surgery, King Faisal Heart Institute KFSHRC, Riyadh, KSA
} *Corresponding author: Mohammed A Takroni, Department of Physical Rehabilitation, KFSHRC, Riyadh, KSA, Tel: 00966555491591; E-mail:
mtaroni@kfshrc.edu.sa

Received: 17 Aug, 2020 | Accepted: 31 Oct, 2020 | Published: 09 Nov, 2020

Citation: Takroni MA, Albarrati A, Akomolafe T, Al Enazy M (2020) The Effect of Early Mobilization on ICU and Hospital Length of Stay and Its Impact on the Cost of Care in Post-Open Heart Surgery Patients: A Randomized Control Trial (RCT). J Heart Health 7(1): dx.doi.org/10.16966/2379-769X.157

Copyright: (C) 2020 Takroni MA, et al. This is an open-access article distributed under the terms of the Creative Commons Attribution License, which permits unrestricted use, distribution, and reproduction in any medium, provided the original author and source are credited.

\begin{abstract}
Introduction: Early Mobilization (EM) of patients in Intensive Care Unit (ICU) has received considerable attention in scientific literature over the past several years. It has been reported that EM decrease Hospital Length of Stay (LOS).
\end{abstract}

Aim of the study: To explore the effect of early mobilization for post open heart surgery patients on hospital and ICU length of stay and its influence on cost effectiveness.

Methods: 41 male and female patients with mean age $(45.95 \pm 13.3)$ were recruited from King Faisal Specialist Hospital and Research Center (KFSHRC). Participant were randomly assigned to one of the two groups; Group I $(n=21)$, Early intervention group program started 4-6 hours post extubation as early Cardiac Rehabilitation (CR) intervention, or Group II $(n=20)$, The standard care group to be seen 9-24 hours post extubation as usual standard care of the hospital.

Intervention: Both groups had the same intervention of cardiac rehabilitation program that included; Aerobic exercises, strengthen exercises, gait training and education. This program was modified from the American Association of Cardiovascular and Pulmonary Rehabilitation (AACVPR).

Outcome measures: Number of days in Intensive Care Unit Hospital Length of Stay and cost effectiveness were calculated by identifying the average cost of one day in the ICU and in the hospital.

Results: Early intervention group (Group I) showed significantly lower number of days in ICUs (2.14 \pm 1.03$)$ compared to standard care group (5 \pm $0.48), p<0.000$. Group I, also showed significantly less hospital LOS $(6.56 \pm 1.63)$ compared to Group II $(8.73 \pm 1.67), p<0.000$. The results of this study showed that the cost saving time spent in the ICU for Group I; 15.327 . Group I spent lesser number of days ( $2.14 \pm 0.04$ days) in the ICU as compared to Group II $(2.86 \pm 0.55)$ thus saving approximately $45.76 \%(\$ 16,511.84)$ in the cost of hospital care and $53.38 \%(\$ 17,538.56)$ in the cost of ICU care.

Conclusion: Study concluded that early mobilization intervention in post-operative open heart surgery patients is safe while positively influencing clinical outcomes, functional recovery, early discharges from the ICUs and the Hospital and ultimately reducing the cost of care.

Keywords: Valve replacement; Cardiac rehabilitation; ICU length of stay; Hospital length of stay; Cost effectiveness

\section{Introduction}

Cardiovascular diseases in Saudi Arabia have a major economic transition due to significant urbanization in recent years [1] and the proportion of individuals living in urban centers has doubled in the past decade $[2,3]$. This rapid urbanization has been associated with a rise in the burden of cardiovascular diseases; however, the national preventive health system and screening programs have trailed behind
[4]. With several thousand cases of all types of open-heart surgery being accomplished each year in Saudi Arabia, there has been a parallel expansion in Cardiology services along with considerable expansion in the number and size of cardiac centers all over the Kingdom [5]. Cardiac surgery is a relatively expensive surgical subspecialty required for an inflating number of patients' worldwide. In order to properly serve the growing patient population, it is necessary to 
closely evaluate the availability of the necessary services to go online with the increasing number of surgeries and ICU admissions and to control the costs involved in cardiac surgery [6]. The muscle inactivity has been proved to be an important risk factor for intensive care unit [7]. Recent studies reported that about $20-50 \%$ of critically ill patients experience Intensive Care Unit-Acquired Weakness (ICU-AW) that lead to different disorders caused by polyneuropathy and myopathy after ICU admission [8-10]. Several studies also reported that these disorders may be associated with reductions in health-related quality of life and increased risks of death after hospital discharge [11,12]. Early Mobilization (EM) of patients in the ICUs has received considerable attention in clinical and scientific literature over the past several years.

It has been recognized as a key component in accelerating recovery post major surgeries and plays a great role in enhancing quality of life in patients admitted to ICU [13]. The term "Early Mobilization" refers to the application of Physical Therapy including passive and active mobilization, respiratory muscle training, out of bed mobilization and gait training [14]. In 2013, Hodgson CL, et al. reported that the application of physical activity within the first 2-5 days of critical illness is widely accepted definition of early mobilization [15]. Numerous studies emphasized on the benefits of early mobilization in ICU. In 2013, Berry MJ, et al. reported that early exercise has the potential effect on decreasing the hospital length of stay and improving the level function of ICU patients [16]. A recent systematic review by Dos Santos PMR, et al. anticipated that early mobilization plays an important role in preventing postoperative complications, improving functional capacity and reducing the length of hospital stay of patients who underwent cardiac surgery [17]. Although, safety consideration used to be a major barrier to generalize the early mobilization in clinical practice especially in ICU [18], recent systematic reviews and meta-analysis proved conclusively that early mobilization for ICU patients is safe and had low incidence of adverse events [19-21]. According to the 2018 study by Zhang L, et al. early mobilization in the ICU exerts a positive and safe effect on hospital outcomes for patients who require mechanical ventilation [22]. Similarly, Tipping CJ, et al. proved conclusively that early mobilization for ICU patients is safe [18]. However, few studies reported that calculating costs of Intensive Care Units (ICU) Length of Stay (LOS) has a great impact on analyzing patient characteristics and identification of cost drivers to optimum utilization of resources [7,23]. A recent study by Kilic M, et al. reported that cost estimations for ICU stay are heterogeneous and still revealing that only $5 \%$ of the patients presenting to hospitals are admitted to intensive care unit. It has been reported that The ICU occupied less than ten percent of total hospital beds, yet ICU care represents one third of total health care costs. Although this rate may appear remarkably low, the ICU costs constitute a large portion of total hospital expenses [24]. Studies reported that 3,949 US dollars (US \$) per day is an average cost of hospital stay and an average cost of first day in the ICU is about 10,794.00 US dollars and then plateaus at $\$ 3,968 /$ day by the third day, depending on the need for mechanical ventilation. However, surgical floor costs are estimated to be 1,488 US $\$$ per day [24-26]. King Faisal specialist Hospital and Research Center (KFSHRC) has been recognized as one of the largest tertiary health care facility in the region (Saudi Arabia) and considerably has the same average cost for patients care due to the high risk conditions that have been operated and admitted to the surgical ICU [27]. Despite all the evidences about the optimistic effect of early mobilization on health outcomes and quality of life in patients admitted to ICU, it is not yet clinically proposed in many health care facilities in Saudi Arabia and most of the gulf region. And the cost effectiveness of early mobilization on ICU and hospital length of stay has not yet has a wide considerable attention in our clinical and scientific literature in Saudi Arabia over the past several years. Therefore, the aim of this study was to explore the effect of early mobilization for post open heart surgery patients on hospital and ICU length of stay and its influence on cost effectiveness.

\section{Methods}

\section{Study design}

This study is a single blinded RCT interventional study.

\section{Ethical approval and consent form}

Ethical approval was obtained from the Research Advisory Council of King Faisal Specialist Hospital and Research Centre (KFSHRC) in Saudi Arabia. All participants were asked to complete and sign a consent form that included an agreement to participate in the study. Explanation of the study, adverse events and the right to withdraw from the study at any time were done and included in the form.

\section{Subjects recruitment}

41 subjects (22 females and 19 males) were consistent with the inclusion criteria and were recruited from KFSHRC see CONSORT diagram (Figure 1). All participants were diagnosed with Rheumatic Heart Disease (RHD) and underwent open heart surgery; Aortic valve replacement (AVR), Mitral Valve Replacement (MVR), or Tricuspid Valve Replacement (TVR). All subjects were recruited from KFSHRC intensive care units; Cardiac Surgical Intensive Care Unit (CSICU) and Cardiovascular Step-down Unit (CVSD), Riyadh, Kingdome of Saudi Arabia (KSA).

\section{Sample size}

The sample size was estimated calculated using a minimal difference in the length of stay in the intensive Care Unit (ICU) of critically ill patients. Power analysis was set at $90 \%$ at an alpha level of $p<0.05$.

\section{Inclusion criteria}

- Post open heart surgery: Only post valves replacement

- Same surgery technique (through med-sternum)

- Age group 30-60

- Hemodynamic stable (Stable vital signs, normal temperature, etc.)

- No post-operative complication

\section{Exclusion criteria}

- Ejection Fraction $<35 \%$

- Any Male/female patient $>60$

- Intubation period $>6$ hours post operation

- Hemodynamic unstable

- Mental health disorders

- Any post-surgical complications (generalized muscle weakness, hemiplegic, or wound infection of the sternum or leg.

- Any post-operative complications.

\section{Randomization}

All participants were randomly assigned to one of the two groups using a consecutive sampling. Group I: Started early mobilization intervention 4-6 hours post extubation, while Group II: followed the standard practice; started 9-24 hours post extubation. 


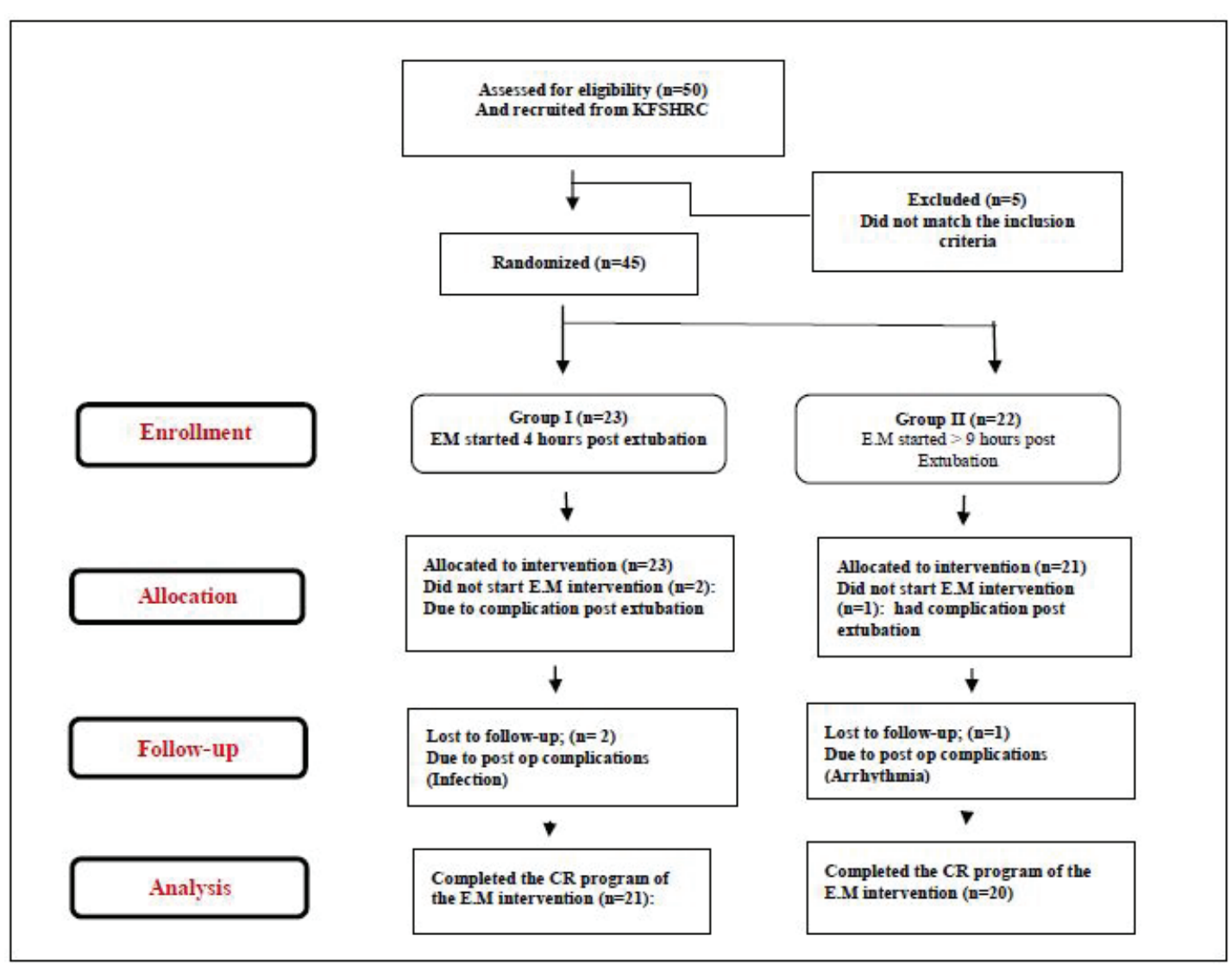

Figure 1: Consort flow diagram of participant's recruitment.

\section{Intervention}

All participants post open heart surgery (valves surgery) who have been referred for Cardiac Rehabilitation Program (CRP) were seen using KFSHRC, Cardiac Rehabilitation program of early mobilization intervention. The program was a $4-5$ days that included; patients assessment, breathing exercise using" Spirometer", Active Range of Motion (AROM) exercise (10-15 repetition hip flexion, extension, abduction, adduction, ankle pumping exercises for the lower extremities in addition to elbow flexion, extension, and shoulder elevation for the upper extremities), early mobilization of sitting on edge of bed or out to the chair, sit to stand (2-5 times), marching in a place, and gait training (100-300 meters). All these exercises were adapted from the American Association of Cardiovascular and Pulmonary Rehabilitation (AACVPR) [28]. Exercises were applied gradually and progressively within four to five days see table 1 . Both group had same exercise program, however, group I has been seen earlier (4-6 hours post extubation) compared to group II who have been seen $>9$ hours.

\section{Outcome measure}

The outcome measures were; the numbers of hours that each patient spent in the surgical ICU from the admission till the discharge. The Length of Hospital Stay (LOS) was also detected by calculating the number of days that each patient hospitalized by calculating the total number of days from day of surgery till day of discharge from the hospital. The cost effectiveness of each patient in the ICU and hospital LOS was calculated as well. Each day in the hospital has a cost depending on the date (first day or second day) the place (ICU or hospital unit), thus the cost of each day in ICU and/or in the hospital unit was identified then the total numbers of days were calculated.

\section{Data collection and statistical analysis}

All collected data were analyzed using SPSS (version 20, IBM, Armonk, NY). All data were tested for normal distribution. Differences in demographic characteristic between participants in the sample were explored by comparing means. Repeated measure analysis of variance (ANOVA) was used to compare all means [29]. The significant level was set at $p<0.05$ and data is presented as mean and standard deviation (mean $\pm \mathrm{SD}$ ).

\section{Results}

A total of 50 participants were approached and consented to participate in the study, only 41 (22 females and 19 males) were consistent with the inclusion criteria and were randomly assigned to one of the two groups. Group I; the early mobilization intervention group $(n=21)$ or Group II; the standard care group $(n=20)$. The demographic data is displayed in table 2. Types of open heart surgery procedures were Aortic Valve Replacement (AVR) for E.M group were $45 \%$ versus $55 \%$ for standard care group, Mitral Valve Replacement (MVR) were $64.7 \%$ versus $41.1 \%$ and Tricuspid Valve Replacement (TVR) were $33.3 \%$ versus 66.7 , see table 3 . None of the variables showed significant differences between the two groups. Both groups had similar age, $p<0.48$, there were no significant difference between the two groups, in gender $p<0.17$ nor in the Body Mass Index (BMI), $p<0.54$. There were no statistically significant differences between the 
Table 1: The intervention description for the two groups.

\begin{tabular}{|c|c|c|c|c|c|c|}
\hline & Ativitis & & $\mathbf{F}$ & I & $\mathbf{T}$ & $\mathbf{T}$ \\
\hline & Acnvines & & Frequency & Intensity & Time & Type \\
\hline & $\begin{array}{l}\text { Day I: } 4-6 \text { hours } \\
\text { post extubation }\end{array}$ & $\begin{array}{l}\text { Breathing } \\
\text { Spirometer } \\
\text { AROM exercise: both upper and } \\
\text { lower limbs } \\
\text { Sitting upright on bed or out on chair } \\
\text { if possible }\end{array}$ & $\begin{array}{l}\text { Daily: } 5-10 \\
\text { Repetition for } \\
\text { each limb } \\
\text { Once/day }\end{array}$ & $\begin{array}{l}20 \% \text { below the } \\
\text { target HR } 60 \% \text { of } \\
\text { HR max Borg scale } \\
\text { (RPE): }<11\end{array}$ & $10-15 \mathrm{~min}$ & $\begin{array}{l}\text { AROM } \\
\text { Exercises }\end{array}$ \\
\hline Groun 1 & Day II & $\begin{array}{l}\text { Breathing } \\
\text { Spirometer } \\
\text { AROM exercise: both upper and } \\
\text { lower limbs } \\
\text { Sitting out on chair } \\
\text { Sit-stand } \\
\text { Walking (few steps) }\end{array}$ & $\begin{array}{l}\text { Daily: } 10-15 \\
\text { Repetition for } \\
\text { each limb. } \\
\text { Once/day }\end{array}$ & $\begin{array}{l}20 \% \text { below the } \\
\text { target HR } 60-75 \% \\
\text { of HRmax Borg } \\
\text { scale (RPE): }<11\end{array}$ & $10-15 \mathrm{~min}$ & $\begin{array}{l}\text { AROM } \\
\text { Exercises }\end{array}$ \\
\hline ו & Day III & $\begin{array}{l}\text { AROM exercise: both upper and } \\
\text { lower limbs } \\
\text { Sitting out on chair } \\
\text { Sit-stand } \times 2-5 \\
\text { Walking } 100-200 \text { meters }\end{array}$ & $\begin{array}{l}\text { Daily: } 10-15 \\
\text { Repetition for } \\
\text { each limb. } \\
\text { Once/day }\end{array}$ & $\begin{array}{l}20 \% \text { below the } \\
\text { target HR } 60-75 \% \\
\text { of HRmax Borg } \\
\text { scale (RPE): }<11\end{array}$ & $10-15 \mathrm{~min}$ & AROM Exercise \\
\hline & Day IV & $\begin{array}{l}\text { AROM exercise: both upper and } \\
\text { lower limbs } \\
\text { Sitting out on chair } \\
\text { Sit-stand } \times 2-5 \\
\text { Walking } 100-200 \text { meters }(m)\end{array}$ & $\begin{array}{l}\text { Daily: } 10-15 \\
\text { Repetition for } \\
\text { each limb }\end{array}$ & $\begin{array}{l}\text { The target HR } \\
60-75 \% \text { of HRmax } \\
\text { Borg scale (RPE): } \\
<11\end{array}$ & $15-20 \mathrm{~min}$ & $\begin{array}{l}\text { AROM } \\
\text { Exercises Gait } \\
\text { Training }\end{array}$ \\
\hline & Day V & $\begin{array}{l}\text { Sit-stand } \times 2-5 \\
\text { Walking } 200-300 \mathrm{~m} \\
\text { Up down stair } 10 \text { levels } \\
\text { Bike } 5-10 \text { min }\end{array}$ & $\begin{array}{l}\text { Daily: } 10-15 \\
\text { repetition } \\
\text { Once /day }\end{array}$ & $\begin{array}{l}\text { The target HR } \\
60-75 \% \text { of HRmax } \\
\text { scale (RPE): }<11\end{array}$ & $15-20 \mathrm{~min}$ & $\begin{array}{l}\text { AROM } \\
\text { Exercises Gait } \\
\text { Training UP } \\
\text { and down } \\
\text { stairs }\end{array}$ \\
\hline & $\begin{array}{l}\text { Day I: } \\
\text { 9>hours post } \\
\text { extubation }\end{array}$ & $\begin{array}{l}\text { Breathing } \\
\text { Spirometer } \\
\text { Sitting upright on bed or out on chair } \\
\text { if possible }\end{array}$ & $\begin{array}{l}\text { Daily: } 5-10 \\
\text { Repetition for } \\
\text { each limb Once/ } \\
\text { day }\end{array}$ & $\begin{array}{l}20 \% \text { below the } \\
\text { target HR } 60 \% \text { of } \\
\text { HR max Borg scale } \\
\text { (RPE): }<11\end{array}$ & $10-15 \mathrm{~min}$ & $\begin{array}{l}\text { AROM } \\
\text { Exercises }\end{array}$ \\
\hline & Day II & $\begin{array}{l}\text { Breathing } \\
\text { Spirometer } \\
\text { AROM exercise: both upper and } \\
\text { lower limbs } \\
\text { Sitting out on chair } \\
\text { Sit-stand } \\
\text { Walking (few steps) }\end{array}$ & $\begin{array}{l}\text { Daily: } 10-15 \\
\text { Repetition for } \\
\text { each limb. Once/ } \\
\text { day }\end{array}$ & $\begin{array}{l}20 \% \text { below the } \\
\text { target HR } 60-75 \% \\
\text { of HRmax Borg } \\
\text { scale (RPE): }<11\end{array}$ & $10-15 \mathrm{~min}$ & $\begin{array}{l}\text { AROM } \\
\text { Exercises }\end{array}$ \\
\hline Group II & Day III & $\begin{array}{l}\text { AROM exercise: both upper and } \\
\text { lower limbs } \\
\text { Sitting out on chair } \\
\text { Sit-stand } \times 2-5 \\
\text { Walking } 100-200 \text { meters }\end{array}$ & $\begin{array}{l}\text { Daily: } 10-15 \\
\text { Repetition for } \\
\text { each limb. Once/ } \\
\text { day }\end{array}$ & $\begin{array}{l}20 \% \text { below the } \\
\text { target HR } 60-75 \% \\
\text { of HRmax Borg } \\
\text { scale (RPE): }<11\end{array}$ & $10-15 \mathrm{~min}$ & AROM Exercise \\
\hline & Day IV & $\begin{array}{l}\text { AROM exercise: both upper and } \\
\text { lower limbs } \\
\text { Sitting out on chair } \\
\text { Sit-stand } \times 2-5 \\
\text { Walking } 100-200 \text { meters }(m)\end{array}$ & $\begin{array}{l}\text { Daily: } 10-15 \\
\text { Repetition for } \\
\text { each limb. Once/ } \\
\text { day }\end{array}$ & $\begin{array}{l}\text { The target HR } \\
60-75 \% \text { of HRmax } \\
\text { Borg scale (RPE): } \\
<11\end{array}$ & $15-20 \mathrm{~min}$ & $\begin{array}{l}\text { AROM } \\
\text { Exercises Gait } \\
\text { Training }\end{array}$ \\
\hline & Day V & $\begin{array}{l}\text { Sit-stand } \times 2-5 \\
\text { Walking } 200-300 \mathrm{~m} \\
\text { Up down stair } 10 \text { levels } \\
\text { Bike } 5-0 \text { min }\end{array}$ & $\begin{array}{l}\text { Daily: } 10-15 \\
\text { repetition Once } \\
\text { /day }\end{array}$ & $\begin{array}{l}\text { The target HR } \\
60-75 \% \text { of HRmax } \\
\text { scale (RPE): }<11\end{array}$ & $15-20 \mathrm{~min}$ & $\begin{array}{l}\text { AROM } \\
\text { Exercises Gait } \\
\text { Training UP } \\
\text { and down } \\
\text { stairs }\end{array}$ \\
\hline
\end{tabular}


Table 2: Demographic characteristics of the study population.

\begin{tabular}{|l|c|c|c|}
\hline & $\begin{array}{c}\text { Group I (n=21) Mean } \\
(\text { SD) }\end{array}$ & $\begin{array}{c}\text { Group II (n=21) Mean } \\
\text { (SD) }\end{array}$ & $p$ value \% \\
\hline Age & $42.90 \pm 14.05$ & $45.95 \pm 13.26$ & $p<0.48$ \\
\hline Gender & $21 \pm 0.49$ & $20 \pm 0.50$ & $p<0.17$ \\
\hline BMI & $27.09 \pm 3.31$ & $28.06 \pm 6.22$ & $p<0.54$ \\
\hline
\end{tabular}

Table 3: Types of valves procedure.

\begin{tabular}{|l|c|c|c|}
\hline $\begin{array}{c}\text { Types of } \\
\text { procedures }\end{array}$ & E.M group (n=20) & $\begin{array}{c}\text { Standard care group } \\
(\mathbf{n = 2 1 )}\end{array}$ & Total \\
\hline AVR & $9(45 \%)$ & $11(55 \%)$ & 20 \\
\hline MVR & $11(64.7 \%)$ & $7(41.1 \%)$ & 18 \\
\hline TVR & $1(33.3 \%)$ & $2(66.7 \%)$ & 3 \\
\hline Total & 21 & 20 & 41 \\
\hline
\end{tabular}

two groups in the number of intubation hours; Group I: $6.38 \pm 0.59$ and Group II: $6.85 \pm 0.81$ hours, $p>0.40$.

The early intervention group (Group I) significantly showed less number of days in the ICUs $(2.14 \pm 1.03)$ compared to the standard care (Group II) which showed more days in the ICUs $(5 \pm 0.48)$, $p<0.000$. The results also showed statistically significant difference between the two groups in the hospital LOS. Early intervention group had significantly less hospital length of stay $(6.56 \pm 1.63)$ days compared to the standard care group $(8.73 \pm 1.67)$ days, $p<0.000$ see table $4 \&$ figure 2 .

Furthermore, the intervention group incurred significantly less costs during their hospital stay $(\$ 19,573.20)$ as compared to the standard care group $(\$ 36,085.04)$. Consequently, early mobilization intervention saved approximately $\$ 16,511.84$. The early mobilization group also incurred less cost for ICU stay $(\$ 15,317.52)$ as compared to the standard group $(\$ 32,856.08)$ thus saving $\$ 17,538.56$ see table 4 .

\section{Discussion}

The findings of the current study are consistent with studies revealing that early mobilization for ICU patient is safe and has positive outcomes on quality of life $[17,18]$. The main findings of this study showed that the early intervention group reveals a statistically significant difference in ICU and hospital length of stay when compared to the standard care group.

Most of the empirical evidences highlighted the importance of early mobilization for ICU patients with some pertinent distinction. Some studies concluded that there is a divide between ICU clinicians who wish to implement early mobilization based on current evidence while on the other hand are clinicians who believe that early mobilization is an intervention that should be tested in a large patient-centered trial in order to determine long term outcomes including functional recovery $[15,17]$.

The results of this study revealed that early mobilization intervention for post open heart surgery patients improved short-term physical function, reduced post-operative complications and the number of days spent in the surgical ICU as well as reduced the total hospital length of stay and ultimately decreased the cost. In 2007 Bigatello
Table 4: ICU, hospital length of stay and cost.

\begin{tabular}{|c|c|c|c|}
\hline & Group I ( $n=21)$ & Group II $(n=20)$ & $p$ value \\
\hline $\begin{array}{l}\text { No of days in ICU: } \\
\text { COST: }\end{array}$ & $\begin{array}{l}2.14 \pm 1.03 \\
\$ 15,317.52\end{array}$ & $\begin{array}{l}5.00 \pm 0.48 \\
\$ 32,856.08\end{array}$ & 0.000 \\
\hline $\begin{array}{l}\text { No of days in Hospital: } \\
\text { COST: }\end{array}$ & $\begin{array}{l}6.56 \pm 1.63 \\
\$ 19,573.20\end{array}$ & $\begin{array}{l}8.73 \pm 1.67 \\
\$ 36,085.04\end{array}$ & 0.000 \\
\hline Total cost & $\$ 34,890.72$ & $\$ 68.941 .12$ & 0.000 \\
\hline
\end{tabular}

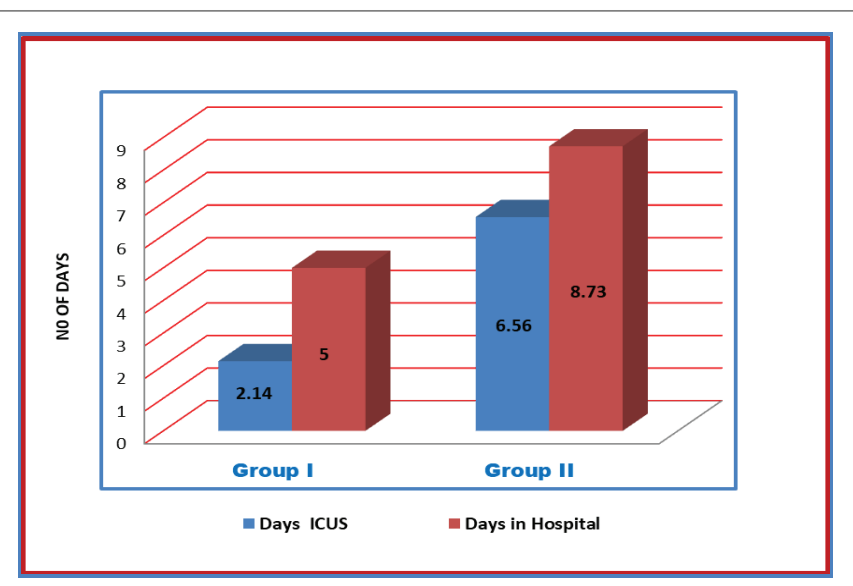

Figure 2: Display of ICUs and hospital length of stay.

LM, et al. reported that the average ICU Length of Stay is about 3.3 days and for every day spent in an ICU bed, the average patient spent an additional 1.5 days in a non-ICU bed [30]. As a result of early mobilization intervention in the post-operative patients as presented in our study whereby the intervention commenced between 4-6 hours post extubation, the patients stayed 2.14 days in the ICU as compared to the standard care group of patients who stayed 6.56 days.

The average cost of an ICU stay is estimated to be US $\$ 10,794.00$ for the first day and then plateaus at US $\$ 3,968 /$ day by the third day. The current study revealed that early mobilization showed a cost saving of US $\$ 17,538$ (about $53 \%$ of total ICU cost). The early mobilization group spent 2.14 days in the ICU with an estimated cost of $\$ 15,317.32$ per patient. The standard care group on the other hand, is estimated to cost $\$ 32,856.08$ per patient. As a result of the implementation of the EM protocol, the study showed that the Hospital is able to save a total of $\$ 17,538.56$ per patient per ICU stay.

It has been reported that cost effectiveness in the ICUs constitute a large portion of total hospital costs [24,31]. However, evidences reported that ICU admission is one of the most cost effectiveness in the hospital admission as a result of many required equipment that may need to be attached to the patient such as mechanical ventilation $[23,32]$. In this study, the results indicated that early intervention group spent less days in the ICU (approximately 3 days shorter than the standard care group), a result of applying early mobilization. Hereby suggesting that early mobilization is safe and effective, evidenced by a $45.76 \%(\$ 16,511.84)$ reduction in the cost of care. The current study showed that early mobilization if successfully implemented will enhance delivery of quality of care with positive implication and benefits to all stakeholders involved in managing ICU patients. Therefore, the outcomes of this study may add to the existing 
evidences the important of early mobilization intervention to critically ill patients and to post open heart surgery patients.

\section{Conclusion}

The results of this study add to the emerging evidence that early mobilization intervention is safe, effective and has a prodigious influence in decreasing the length of ICU stay, reducing the overall length of hospital stay, improving the patient outcomes including the quality of life as well as decreasing the financial burden of care. By implementing EM, patients were discharged early from the ICU as well as from the hospital with significant decrease in the cost of care thus highlighting its potential benefits as a cost effectiveness measure.

\section{Limitations}

The current study is a single blind RCT study that used single center experience (KFSHRC) in the capital city of Saudi Arabia. Therefore, these study findings cannot be generalized to the entire population of Kingdom of Saudi Arabia (KSA). This study is only restricted to post-open valve heart surgery patients hence cannot be extrapolated to other subset of patient categories.

\section{Future Research}

Recommendations for further studies will include a reproducibility studies at more than one hospital or centers. Additionally, if similar studies were conducted on other open-heart surgeries such as post Coronary Bypass Graft (CABG) patients, it may add to existing evidence in the literature.

\section{Declaration of Competing Interest}

The authors declare that there are no relationships that could be construed as a conflict of interest.

\section{References}

1. Yusuf S, Reddy S, Ounpuu S, Anand S (2001) Global burden of cardiovascular diseases: part I: general considerations, the epidemiologic transition, risk factors, and impact of urbanization. Circulation 104: 2746-2753.

2. Al-Nuaim AA, Bamgboye EA, Al-Rubeaan KA, Al-Mazrou Y (1997) Overweight and obesity in Saudi Arabian adult population, role of socio-demographic variables. J Community Health 22: 211-223.

3. Arnlov J, Evans JC, Meigs JB, Wang TJ, Fox CS, et al. (2005) Low-grade albuminuria and incidence of cardiovascular disease events in nonhypertensive and non-diabetic individuals: the Framingham Heart Study. Circulation 112: 969-975.

4. De Jonghe B, Sharshar T, Lefaucheur J, Authier F, Durand-Zaleski I, et al. (2002) Paresis acquired in the intensive care unit: a prospective multicenter study. JAMA 288: 2859-2867.

5. Ali NA, O'Brien JM, Hoffmann SP, Phillips G, Garland A, et al. (2008) Acquired weakness, handgrip strength, and mortality in critically ill patients. Am J Respir Crit Care Med 178: 261-268.

6. Gaziano TA (2005) Cardiovascular disease in the developing world and its cost-effective management. Circulation 112: 3547-3553.

7. De Jonghe B, Lacherade J, Sharshar T, Outin H (2009) Intensive care unit-acquired weakness: risk factors and prevention. Crit Care Med 37: S309-S315.

8. Denehy L, Lanphere J, Needham DM (2017) Ten reasons why ICU patients should be mobilized early. Intensive Care Med 43: 86-90.
9. Baldwin MR, Reid MC, Westlake AA, Rowe JW, Granieri EC, et al. (2014) The feasibility of measuring frailty to predict disability and mortality in older medical intensive care unit survivors. J Crit Care 29: 401-408.

10. Puthucheary ZA, Rawal J, McPhail M, Connolly B, Ratnayake G, et al. (2013) Acute skeletal muscle wasting in critical illness. JAMA 310: 1591-1600.

11. Jolley SE, Bunnell AE, Hough CL (2016) ICU-Acquired Weakness. Chest 150: 1129-1140.

12. Fan E, Dowdy DW, Colantuoni E, Mendez-Tellez PA, Sevransky JE, et al. (2013) Physical complications in acute lung injury survivors: a two-year longitudinal prospective study. Crit Care Med 42: 849-859.

13. Truong AD, Fan E, Brower RG, Needham DM (2009) Bench-tobedside review: mobilizing patients in the intensive care unit--from pathophysiology to clinical trials. Crit Care 13: 216.

14. Kress JP (2009) Clinical trials of early mobilization of critically ill patients. Crit Care Med 37: S442-S447.

15. Hodgson CL, Berney S, Harrold M, Saxena M, Bellomo R (2013) Clinical review: early patient mobilization in the ICU. Crit Care 17: 207.

16. Berry MJ, Morris PE (2013) Early exercise rehabilitation of muscle weakness in acute respiratory failure patients. Exerc Sport Sci Rev 41: 208-215.

17. Dos Santos PMR, Ricci NA, Suster EAB, Paisani DM, Chiavegato LD (2017) Effects of early mobilisation in patients after cardiac surgery: a systematic review. Physiotherapy 103: 1-12.

18. Tipping CJ, Harrold M, Holland A, Romero L, Nisbet T, et al. (2017) The effects of active mobilization and rehabilitation in ICU on mortality and function: a systematic review. Intensive Care Med 43: 171-183.

19. Nydahl P, Sricharoenchai T, Chandra S, Kundt FS, Huang M, et al. (2017) Safety of patient mobilization and rehabilitation in the intensive care unit. Systematic review with meta-analysis. Ann Am Thorac Soc 14: 766-777.

20. Castro-Avila AC, Seron P, Fan E, Gaete M, Mickan S (2015) Effect of early rehabilitation during intensive care unit stay on functional status: Systematic review and meta-analysis. PLoS One 10: e0130722.

21. Kayambu G, Boots R, Paratz J (2013) Physical therapy for the critically ill in the ICU: a systematic review and meta-analysis. Crit Care Med 41: 1543-1554.

22. Zhang L, Hu W, Cai Z, Liu J, Wu J, et al. (2019) Early mobilization of critically ill patients in the intensive care unit: A systematic review and meta-analysis. PLoS One 14: e0223185.

23. Aygencel G, Turkoglu M (2011) Characteristics, outcomes and costs of prolonged stay ICU patients. J Medical Surg Intensive Care Med 2: 53-58.

24. Kilic M, Yuzkat N, Soyalp C, Gulhaş N (2019) Cost analysis on intensive care unit costs based on the length of stay. Turk J Anaesthesiol Reanim 47: 142-145.

25. Morris P (2007) Moving our critically ill patients: mobility barriers and benefits. Crit Care Clin 23: 1-20.

26. Lord RK, Mayhew CR, Korupolu R, Mantheiy EC, Friedman MA, et al. (2013) ICU early physical rehabilitation programs: financial modeling of cost savings. Crit Care Med 41: 717-724. 
27. King Faisal Specialist Hospital and Research Centre (KFSHRC) (2017) Open Data Library. KFSHRC, Saudi Arabia.

28. Thomas RJ, King M, Lui K, Oldridge N, Piña IL, et al. (2007) AACVPR/ ACC/AHA 2007 performance measures on cardiac rehabilitation for referral to and delivery of cardiac rehabilitation/secondary prevention services. Circulation 116: 1611-1642.

29. Sawyer SF (2009) Analysis of variance: The fundamental concepts. J Man Manip Ther 17: 27E-38E.
30. Bigatello LM, Stelfox HT, Berra L, Schmidt U, Gettings EM (2007) Outcome of patients undergoing prolonged mechanical ventilation after critical illness. Crit Care Med 35: 2491-2497.

31. AVERT Trial Collaboration group (2015) Efficacy and safety of very early mobilization within $24 \mathrm{~h}$ of stroke onset (AVERT): a randomized controlled trial. Lancet 386: 46-55.

32. Kahn JM, Rubenfeld GD, Rohrbach J, Fuchs BD (2008) Cost savings attributable to reductions in intensive care unit length of stay for mechanically ventilated patients. Med Care 46: 1226-1233. 